\title{
Por um modo de vida alegre
}

\section{Towards a joyful way of life}

https://doi.org/10.34112/2317-0972a2017V35n70p147-157

\section{Renata Ferreira da Silva ${ }^{1}$}

RESUMO: Este texto² arrisca pensar uma dimensão ética, entendida como modo de vida, como modo de existência dado na política de relações que experimentamos. Spinoza e Deleuze são afetos que norteiam um pequeno percurso filosófico concatenando corpo, alegria e potência de agir numa dimensão ética da educação. Aqui já não podemos nos amarrar mais a nenhum discurso salvacionista para a educação, a nenhum futuro que nos permita experimentar a alegria. Defende-se ativar nossas potências agora.

Palavras-chave: Corpo; potência; ética; educação; alegria.

ABSTRACT: The text approaches an ethic dimension, understood as a way of life, as a way of existence given in the political relations we experience. Spinoza and Deleuze are affects that guide a brief philosophical journey connecting body, joy and the power to act in an ethical dimension of education. Here we can no longer tie ourselves to an idea of salvation for education, to any future that allows us to experience joy. We must activate potencies now. KEYWORDS: Body; potency; ethics; education; joy.

1. Universidade Federal de Tocantins, Palmas, TO, Brasil.

2. Durante o processo de avaliação deste artigo, uma versão do texto foi publicada nos anais do $7^{\circ} \mathrm{SBECE} /$ Canoas - RS. 
É melhor ser alegre que ser triste, alegria é a melhor coisa que existe!

Vinicius de Moraes

Às vezes notamos que um dos desafios da Educação é superar certa tristeza. Observo atenta, num primeiro contato, um clima de cansaço, olhares enfadonhos e corpos "sem vontade de se mover" nas formações para professores/as das quais venho participando. Não é preciso ser triste para ser professor/a, alerta Corazza (2008) em uma palestra ${ }^{3}$ durante uma formação continuada de professores. Ao contrário, é preciso ser alegre. Não por uma necessidade moral, mas por uma necessidade vital.

Não vou insistir que uma provocação para a educação passa por uma etiqueta feliz, um conjunto de normas e preceitos morais; ao contrário, vou arriscar pensar que passa por uma dimensão ética entendida como um modo de vida, modo de existência dado na política de relações que experimentamos, pelos afetos.

Neste texto, proponho me deixar afetar por Spinoza, Deleuze, Corazza e Garcia, realizando um percurso filosófico que concatena corpo, alegria e potência de agir numa dimensão ética da educação. Estou menos interessada aqui em propor a alegria como uma obrigação a cumprir, ou como um "jogo do contente", no qual disfarçamos as mazelas da vida para dizer "eu sou alegre". Interessa entender como a alegria impulsiona a potência de agir e está conectada à nossa força, à capacidade de produção de nós mesmos, ao desejo e à liberdade.

Como uma vida conquista seu próprio pensamento? Como podemos nos tornar livres? E qual a força da alegria nessa razão? Um método de ensino, uma forma de ser docente, parece sempre estar em busca de uma maneira mais eficiente em direção a uma meta final. Oscilamos entre obediência e culpa, mérito e demérito. Mas, "o pensamento livre estaria justamente isento da necessidade de obedecer, sendo, portanto, vital, não comprometido" (GARCIA, 2012, p. 158).

Vamos suspender por um momento a culpa que nós docentes atribuímos a nós e aos colegas de profissão sempre que fazemos qualquer crítica à Educação. Vamos suspender, ainda que temporariamente, a conjugação do verbo "dever", a ideia que estamos todos devendo fazer algo que não foi feito, ou ainda, conhecer algo que nos é desconhecido.

3. Palestra realizada por Sandra Mara Corazza na UNIFEBE, Brusque, SC, em 22 de julho de 2008. 
Dado que temos encontrado muitas mazelas na área da Educação (e são muitas), a questão é como, em um espaço menor, ou seja, no lugar onde nós trabalhamos atualmente, podemos produzir a nós mesmos. Pensamos em coisas simples, e chegar ao simples não é fácil. Pensamos naquele momento no qual vamos organizar um plano de curso. Pensamos na força dos estudantes ou partimos do fracasso deles? Partimos do que não sabem e deveriam saber? Notamos que a vida deles (e a nossa) foi errada e estamos ali para consertar? Elaboramos um plano grande que dê conta de todos? Que chatice pensar que a vida é sempre errada... E mais, que a todos falta muita coisa. Ora, o que estamos dizendo? Claro que faltam coisas na Educação, nos nossos espaços de atuação! Mas ao desejo não falta nada, e a partir dele poderíamos pensar uma ética na Educação.

Baruch de Spinoza nos ajuda a entender, contudo, que a natureza não age com um fim; age com a mesma necessidade com que existe. Como sua existência, sua ação não tem princípio nem fim. O que chamamos de finalidade é o desejo humano, na medida em que este é considerado a causa eficiente das coisas: "Quanto à causa que chamam final, não se trata senão do próprio apetite humano, enquanto considerado como princípio ou causa primeira de alguma coisa" (E4Pref.) ${ }^{4}$.

Não falta absolutamente nada ao desejo. Isso não quer dizer que somos autossuficientes. Nossa natureza, nossa essência singular, está circunscrita aos agenciamentos. É neles que existimos e expandimos nossa potência porque os encontros são ideias, novidades que fora de nós podem nos forçar a expandir essa potência de existir

O que pode nos mover em torno de uma invenção de nós mesmos? Como conhecer a nossa potência de conhecer?

\section{O CORPO}

Acostumamo-nos a tratar nosso corpo como algo que deve ser disciplinado, dominado, controlado. Será que sabemos o que pode o nosso corpo? A questão, trazida pelo filósofo Baruch de Spinoza nos convida a tomar o corpo, a ultrapassar todo o conhecimento que temos dele e a entender que as potências do corpo seguem paralelas às potências da mente.

4. Escolho citar os fragmentos de Spinoza à maneira dos filósofos que utilizam: $\mathrm{E}=$ Ética seguido dos números 1,2,3 ou 4 para a parte da Ética a que se refere o fragmento. Na sequência teremos $\mathrm{P}=$ Preposição seguida do número; $\mathrm{E}=$ Escólio ou $\mathrm{A}=$ Axioma ou $\mathrm{D}=$ Definição ou Pref. = Prefácio. 
Gilles Deleuze nos ajuda a entender esse paralelismo entre corpo e mente ao afirmar que "[q] uando um corpo encontra outro corpo, uma ideia outra ideia, tanto acontece que as duas relações se compõem para formar um todo mais potente, tanto que um decompõe o outro e destrói a coesão de suas partes" (DELEUZE, 2002, p. 25). Isso quer dizer que participamos de uma ordem de composição e decomposição que se dá a todo o momento, pelos encontros que vamos tendo ao longo de uma vida. Se o que uma mente pode conhecer é correlato com que um corpo pode experimentar percebemos, a partir do estudo da Ética de Spinoza, que podemos tornar a afetividade humana objeto do conhecimento racional e que podemos nos aperfeiçoar eticamente por meio da produção de afetos libertadores. Tudo isso passa pela capacidade de afetar e ser afetado; pelos encontros entre corpos e ideias.

Constituir-se no dado é viver os encontros. Encontros que se vivem de diferentes maneiras: despercebida, forte, marcante, violenta, alegre e/ou triste. Os encontros produzem efeitos, forçam cada corpo a produzir sentido às experiências que (des)organizam um modo de viver. Essa produção de sentidos ao que acontece é um campo extremamente complexo e ininterrupto de enfrentamentos. Trata-se de uma força que está em relação com outra força, que recebe a ação de outra, que age sobre outra. Nesse fluxo, não há como conceber um sujeito como uma identidade original. Posso dizer aqui que não somos um corpo fechado, substancial, ao contrário, somos uma regulação não material. As coisas participam em nós, de nossa regra de relação - certa quadam ratione ${ }^{5}$. Spinoza demonstra isso quando afirma que as partes que compõem o corpo humano não pertencem à essência desse corpo, a não ser enquanto transmitem entre si os movimentos segundo essa proporção, essa regra de relação, e não como indivíduos. Veja só, não estamos imunes aos afetos... E nosso corpo é um corpo complexo no qual se relacionam vários corpos. Tudo isso abre espaço para conexões, fluxos, deslocamentos e movimentos dados por um lado de fora ao invés de fixidez, segurança e verdade original.

Mas como um lado de fora? Há um lado de dentro? Só posso entender que há um lado de dentro se ele for provisório, composto pelas forças do lado de fora. Então seria isso. $\mathrm{O}$ lado de fora diz respeito à força. $\mathrm{E}$ toda força se relaciona com outras forças. Escuto Deleuze (2005, p. 93): “[...] as forças remetem necessariamente a um lado de fora irredutível, que não tem mais sequer forma, feito de distâncias indecomponíveis através das quais uma força age sobre a outra ou recebe a ação

5. Expressão de Baruch de Spinoza - certa relação de proporção entre movimento e repouso. 
da outra." Então vamos nos constituindo à medida que entramos em contato com estas forças. Nós também somos forças que atuam em outras forças. Quando atuam em nós, atribuímos-lhes, na medida em que sofremos suas ações, um sentido singularizado. Há encontros que nos forçam a desorganizar modos conhecidos de viver e pensar. Isso nem sempre é tranquilo, pode ser estranho e angustiante. Eis a vida. Um movimento, uma sequência de enfrentamentos sem paradas. A vida acontece aí, de forma complexa, onde os dados podem ser tomados como forças que afetam o sujeito de diferentes maneiras e perturbam a conhecida organização que denominamos eu. Nos vividos, essas forças também podem não se manifestar. Tudo vai depender dos enfrentamentos e da produção de singularidades dadas em cada encontro, em cada composição. $\mathrm{O}$ - eu imagina, quer, deseja. Na medida em que a ação das forças do lado de fora, que circulam por aí, afetam o corpo, e passam também a circular do lado de dentro e a compor o - eu que imagina, quer e deseja. Isso se dá num eterno movimento, e talvez possa ser alegre.

\section{A Alegria}

Aprendemos com Spinoza que “[...] a alegria é um afeto pelo qual a potência de agir do corpo é aumentada ou estimulada" ( $\left.\mathrm{E}_{4} \mathrm{P}_{41}\right)$. Ou seja, a alegria depende dos bons encontros e está relacionada ao aumento da nossa potência de agir.

Alegres, elevamos a potência do corpo, mudamos de forma, experimentando novos pensamentos, ideias, quereres. Tristes, diminuímos a potência do corpo, nossos conjuntos afetivos não compõem como a nossa potência e experimentamos a estagnação. É que tristes tendemos a colocar algo em posição superior à vida, algo que a julga e a desvaloriza. Alegres, tendemos a ser mais fortes, mais potentes, a conhecermos as causas que nos convêm para nos produzirmos. Pausa: vejam só que a alegria está conectada à produção de nós mesmos/as! Vejam só, ao nosso desejo não falta nada!

Na Ética de Spinoza, a própria essência do ser humano, essa relação entre movimento e repouso em que se relacionam muitos corpos, é desejo e se desenha como um princípio dinâmico que é, em determinados momentos, a conservação de nossa natureza e, em outros, afirmação e expansão da nossa potência. $\mathrm{O}$ que nos move é a busca daquilo que aumenta a nossa potência, nossa vontade de expansão.

O desejo pode se estabelecer ativamente, quando aumenta a potência de existir, ou passivamente, quando a diminui. Quando o desejo é determinado por causas exteriores, ele é passivo. Mas, quando determinado por causas internas, é uma ação. 
Então podemos nos tornar causa adequada de nós mesmos à medida que fortalecemos nosso desejo, aumentando nossa potência de agir e existir. Aqui já não podemos nos amarrar mais a nenhum discurso salvacionista de educação, a nenhum futuro que nos permita experimentar a alegria. É preciso ativar nossas potências no agora.

Quais encontros convêm a cada um de nós? O que pode um corpo? Qual o poder de ser afetado e de afetar de um corpo? Um afeto é uma afecção que faz variar positivamente (alegria) ou negativamente (tristeza) a nossa potência de agir. $\mathrm{O}$ afeto é, então, a experiência de uma transição e, nesse sentido, existem afetos ativos e passivos.

Toda afetividade ativa será caracterizada pela positividade e alegria. Os afetos ativos estão conectados às ideias adequadas, ideias que se explicam pela nossa natureza, que são alegres e não podem nos conduzir a destruição ou diminuição de potência.

Os afetos passivos estão conectados a ideias inadequadas, ideias que não se explicam apenas por nós, mas por causas exteriores a nós. Eles podem ser alegres ou tristes e isso vai depender da compatibilidade ou não entre essas coisas e nós.

As paixões, ou seja, os afetos passivos, mesmo que sejam alegres, são sempre variáveis e nos colocam numa posição dependente em relação ao outro, ao acaso.

[...] fica evidente que somos agitados pelas causas exteriores de muitas maneiras, como ondas do mar agitadas por ventos contrários, somos jogados de um lado para outro, ignorantes de nossa sorte e de nosso destino $\left(\mathrm{E}_{3} \mathrm{P}_{59}\right)$.

As ações, por outro lado, resultam de nossa natureza trazendo autonomia e o exercício de nosso desejo. Nelas experimentamos a intensidade da liberdade quando produzimos a nós mesmos. Aí está a provocação para o conhecimento: um poder de invenção e produção de si mesmo que gera sempre diferenças, novas formas de vida, de pensamento, de existência e de docência.

Num primeiro contato com Spinoza, desenhamos como condições possíveis para a existência uma oposição a tudo que pudesse suprimir a produção de si, uma espécie de "princípio de resistência que atuará não somente perante as coisas exteriores, mas também no seio mesmo da coisa em sua maneira própria de operar sobre o que lhe acontece e de dispor de suas próprias afecções" (BOVE, 2010, p. 69) e uma aptidão à união a um mesmo esforço, numa atitude de "aliança que também vale tanto perante outros indivíduos quanto na ligação e no comércio de corpos que compõe um só e mesmo indivíduo a partir de sua multiplicidade mesma" (BOVE, 2010, p. 69). 
Contudo, essa produção ativa passa por uma compreensão de que uma vida é sempre causa e razão, ainda que parcial, do que lhe acontece, o que reconfigura a perseverança de uma vida mesmo nas afecções contrárias. Uma vida pode colocar os afetos contrários numa ordem tal que não sejam mais contrários, limitantes, mas, alegres e ativos. Uma vida pode transformar os afetos contrários em pensamentos ativos. Encontro aí uma liberdade, um pensar livre que não está orientado pelas forças externas, "pelo encontro fortuito com as coisas", mas que rearranja o mesmo material numa outra ordem "quando está interiormente determinada" ( $\left.\mathrm{E}_{2} \mathrm{P}_{29} \mathrm{E}\right)$. Isso impulsiona a não esperar que alguém ou algo aconteça para sermos felizes em Educação.

Aprendemos com Nietzsche que a alegria está relacionada ao sentimento de uma potência que se eleva devido à uma resistência superada:

[...] O que é bom? - Tudo que aumenta, no homem, a sensação de [potência] ${ }^{6}$, a vontade de [potência], a própria [potência]. O que é mau? - Tudo que se origina da fraqueza. O que é felicidade? - A sensação de que [a potência] aumenta - de que uma resistência foi superada. (NIETZSCHE, 2002, p. 09).

Essa produção de um tipo de vida, de liberdade se dá pelo pensamento? Pensar é poder produzir novos modos de vida, outros modos de existir de forma a produzir liberdade, alegria. Pensar tem corpo? Que modos podem ser inventados?

\section{A POTÊNCIA DE AGIR}

O sentimento que temos é de que a liberdade é uma produção de si. Um si que traz a novidade de gestos de individuação. Não um individuar-se que se separa do mundo, pois isso não acontece. Como modos da natureza, nós nos tornamos cada vez mais o que somos sem estarmos separados do mundo. Como seres essências que têm certa relação, certa proporção entre as partes do corpo, nós nos esforçamos por manter essa relação, por formar essa relação com todo o universo. Nossa origem é esse movimento, essa potência. Sinto que a filosofia prática de Spinoza não descreve o mundo; descobre-o de outra maneira. Como lance de força, ela nos provoca a pensar: somos a causa de nós mesmos?

6. Modifiquei a tradução. Onde constava poder, preferi potência. 
A alegria muitas vezes incomoda, faz barulho, dá risada de coisas simples, tece conexões absurdas, incomoda os sujeitos mais conservadores da Educação. Ao explorar os conteúdos como se fossem labirintos, ao cursar o trajeto das aulas como se habitássemos parques, ao ficcionalizar a Educação e potencializar as trocas, temos mais chances de expandirmos nossa força. Parece-me que podemos produzir paixões alegres, afinal:

A potência de agir é causada pela qualidade afetiva dos encontros: ela é ampliada quando encontramos um corpo que convém a nossa natureza - paixões alegres -, mas é diminuída quando encontramos um corpo exterior que se opõe a nossa natureza paixões tristes. (GARCIA, 2012, p. 164).

Ao tentarmos representar a figura do/a professor/a como um conceito/categoria, nós nos deparamos com a questão da identidade que deseja igualar diferentes sujeitos num determinado modelo. Não há espaço para as singularidades. $\mathrm{O}$ desigual é geralmente posto à margem. Um arquétipo de professor também prevê um arquétipo de estudante. E isso é possível? Na escola parece que sim. $\mathrm{O}$ "ensinar tudo a todos" a que Comenius (2002) se referia na Carta Magna deveria nos estimular a criar nas instituições de ensino oportunidades para que meninas e meninos aprendessem cada um na sua singularidade. Mas como, se estamos tristes e não estamos produzindo nossa singularidade a cada encontro? Como inverter essa dinâmica? Parece-nos que um esforço que seleciona, organiza e busca bons encontros é essencial para experimentarmos alegria, para nos afirmarmos.

As crianças brincam e afirmam a vida. Lançam-se ao indefinido. Permitem-se inventar o dia inteiro. Assim, nossa aposta educativa é estimular nos viventes da escola (estudantes e professores/as) um pensamento mais inventivo, alegre. Uma interrupção das cópias para destacar as singularidades de cada original. Algo que nos distancie de qualquer ideal de sujeito, mas veja, ouça e se relacione com as/nas diferenças. Mais que isso, que aprenda, compartilhe e ensine por experimentações, assim como fazem as crianças. Desejamos uma docência que produza novidades, que instigue a criar para pensar.

Como? Não há nada superior à vida. A partir dessa premissa o convite é para afirmamos a vida de uma forma integral, interpretando o mundo com expressão e pensamento. Afirmar a vida passa por assumir que temos caos dentro de nós. E isso não é um problema. Não é isso que temos que superar. O caos é a condição para uma 
existência cheia de potência, para uma maneira de existir que se entrega à criação incessante com vistas a transpor obstáculos, transvalorar valores e extravasar forças.

O exercício parece ser amar tudo, os bons e os maus encontros, sem culpa e sem ressentimento. Amar a vida mesmo quando é estranha e pesada. Talvez nós tenhamos essa força. Estudar tudo isso traz um gosto leve e uma vontade de rir.

Aí, mais leve, reencontro a palestra:

[...] talvez, seja preciso seguir todas aquelas que, da sua condição de professoras, fazem não um sacrifício a um poder que é sempre triste, que bloqueia a efetivação de suas potências, mas, um cântico à vida, e que, por isso, reinventam todos os gestos, fazem passar fluxos de novidades, atravessam os muros, deslocam os limites, transformam o ofício de educar em um sistema solar e planetário, vivo e móvel. Professoras que cintilam, vibram, viajam, mesmo permanecendo onde sempre estiveram, ao preencher e efetuar a potência de educar, de nome Alegria. (CORAZZA, 2008, p. 03).

O esforço por afirmar a existência do nosso corpo vem primeiro. É a causalidade interna que nos move para garantir e manter a proporção de repouso e movimento que nos constitui e não o finalismo. Isso muda tanta coisa.... Não sei se quem me lê também pensa assim, mas percebo que os processos educativos estão cheios de finalidade, sejam eles a progressão na carreira para os professores ou a aprovação em exames. O que nos move é o que aumenta nossa potência. $\mathrm{E}$ isso é bom. Isso tem um gosto bom. Tem o gosto da força do mundo inteiro na gente.

Mas o que é a potência de agir? É justamente a saída do domínio das paixões para o domínio das ações. É escapar das ideias inadequadas e conquistar a potência de agir. $\mathrm{O}$ que eu faço com tudo que estudo? Se não for para criar, para criar mais força e mais vida... Para que serve? O servir aqui é da ordem da intensificação da vida, que abre possibilidades e não da ordem das finalidades. Não se trata de uma moral, de um dever ou de uma generalização de uma fórmula do que deve ser feito por todos os seres humanos, uma formação em massa...

Nas conversações com Gilles Deleuze (2013) encontramos a diferença entre moral e ética:

[...] a moral se apresenta como um conjunto de regras coercitivas de um tipo especial, que consiste em julgar ações e intenções referindo-se a valores transcendentes (é certo, é errado...); a ética é um conjunto de regras facultativas que avaliam o que fazemos, o 
que dizemos, em função do modo de existência que isso implica. (DELEUZE, 2013, p. 129-130).

Avanço nesse estudo por uma vontade de querer muito mais forte do que uma vontade de salvação. Deleuze (2002, p. 29) nos ajuda a compreender que tudo aquilo que agrupamos sob uma categoria do mal é, simplesmente, um mau encontro. Não tratamos de bem e mal aqui, mas de bom e mau. Bom e mau tem dois sentidos, um objetivo e outro ligado à diferença de qualidade de modos de existência. $\mathrm{O}$ primeiro trata do que convém ou não convém à nossa natureza, da composição ou decomposição dos encontros. O segundo, do nosso modo de existir. Bom é aquele modo que se esforça tanto quanto pode por organizar encontros, por se unir ao que convém à sua natureza, por aumentar sua potência; mau trata daquele modo que vive ao acaso dos encontros, sofrendo suas consequências, acusando os efeitos que se mostram contrários e revelam sua impotência.

A questão passa por outro lugar, pelo que nós somos capazes, o que está em nossa potência, por uma ética que nos afirma na existência. A ética é um problema de potência e não um problema de dever. E qual nosso desafio? Não dever nada, nem mesmo dever ser alegre... Mas é preciso estar alegre para expandir nosso desejo. Ao desejo nada falta.

\section{REFERÊNCIAS}

BOVE, Laurent. Potência e prudência de uma vida como singularidade em Espinosa. In.:

Espinosa e a psicologia social: ensaios de ontologia política e antropogênese. Belo Horizonte: Autêntica, 2010. p. 63-76.

COMENIUS. Didática Magna. Tradução de Ivone Castilho. Benedetti. 2. ed. São Paulo: Martins

Fontes, 2002

CORAZZA, Sandra Mara. Por que somos tão tristes. In: Currículo na contemporaneidade, 2008, Brusque. Conferência na Formação Continuada. Brusque, SC: UNIFEBE - Centro Universitário de Brusque, 2008. Disponível em: <https://www.researchgate.net/publication/267784814_Por_ que_somos_tao_tristes $>$. Acesso em: 20 ago. 2017.

DELEUZE, Gilles. Conversações. Tradução de Peter Pál Pelbart. 3. ed. São Paulo: Editora 34, 2013. DELEUZE, Gilles. Espinosa, filosofia prática. Tradução de Daniel Lins e Fabien Pascal Lins. São Paulo: Escuta, 2002.

DELEUZE, Gilles. Foucault. Tradução de Claudia Sant’Anna Martins. Revisão de tradução Renato Ribeiro, São Paulo: Brasiliense, 2005. 
GARCIA, Wladimir A. da Costa. Ética e Método. In: SOUZA, Ana Claudia de; GARCIA, Wladimir A. da Costa. A produção de sentidos e o leitor: os caminhos da memória. Florianópolis: NUP/ CED/UFSC, 2012.

NIETZSCHE, Friedrich. O anticristo: ensaio de uma crítica ao cristianismo. Tradução de André Díspore Cancian. Fonte digital. Ateus.net, 2002. Disponível em: <http://www.ebooksbrasil.org/ adobeebook/anticristo.pdf $>$. Acesso em: 19 ago. 2017.

SPINOZA, Benedictus de. Ética. Tradução e notas de Tomaz Tadeu. 3. ed. Belo Horizonte: Autêntica, 2010.

\section{SOBRe A AUTORA}

Renata Ferreira da Silva é atriz, graduada em Licenciatura em Artes Cênicas (Universidade Estadual de Santa Catarina). Tem Mestrado e Doutorado em Educação (Universidade Federal de Santa Catarina). É professora/pesquisadora da Universidade Federal do Tocantins. Tem experiência na área de processos criativos em pedagogia do teatro com pesquisas nos seguintes temas: mímica e teatro físico, filosofia da diferença, educação, ficção e formação de professores. E-mail: renataferreira@uft.edu.br.

Site: https://teatrodemimagens.wixsite.com/renataferreira.

Recebido em 25 de fevereiro de 2017 e aprovado em 19 de maio de 2017. 